\title{
International Encounters: Higher Education and the International Student Experience
}

Edited by Cindy Ann Rose-Redwood and Reuben Rose-Redwood, 2019. Rowman \& Littlefield. ISBN 978-1475839418

Reviewed by Terra Gargano, American University, USA

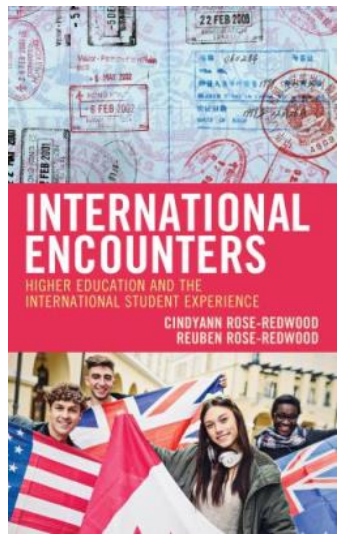

The book is organized into four sections, including International Student Experiences in the US, International Student Experiences in the United Kingdom, International Student Experiences in Australia, and International Student Experiences in Canada, with three research-based articles in each section. Several chapters focus on challenges international students encounter that stem from the degrees of cultural differences between the host and home cultures, the extent to which institutions of higher education create programming that allows for an integrative approach of international students and domestic students, the institutional resources that address the psychological, academic, and cultural needs of all students, and the obstacles international students faced along the road to studying abroad. While some authors tackle topics and issues well-grounded in the international and transcultural higher 
education literature, such as intercultural competency, cultural differences, English language proficiency, academic expectations, racism, stereotyping the Other, and visa status, there are several authors that dive deeper into the labels generally associated with border crossing experiences to develop frameworks that provide a unique lens for further exploring international student experiences.

Collectively, the 13 chapters, six of which are reprints, challenge the deficient model historically associated in the literature with international student experiences, while individual chapters spanning national contexts recognize and focus on the nuances and variations within specific cross-cultural encounters. Most importantly, every chapter privileges the voices of international students, recognizing the conflicting challenges and opportunities that studying abroad presents at times and the need to rethink and deploy an intersectional methodological approach to further understanding student experience. Yet, each author accomplishes this to varying degrees in their research. Through interviews, surveys, focus groups, and participant observations, the contributing authors acknowledge and make meaning from the collective voices shared, at times offering practical implications for university administrators.

The articles in this collection address both macro or institutional perspectives and micro or interpersonal perspectives on international student experiences. From a macro perspective, several authors take a critical stance on the institutionalist perspective generally taken within international education research, and propose instead an internationalist perspective, a student-centered alternative that includes the human, social, and identity capital of students beyond the borders of campus. The authors develop a social interaction continuum model to describe and analyze the social interactions of international students, which includes self-segregation, exclusive global mixing (ethnic and international), inclusive global mixing, and host interaction. The shift in perspective from an institutionalist perspective to an internationalist perspective somewhat invalidates the idea that international student experience can be improved upon if only the host institution would dedicate the time, resources, and programming to bringing host and international students together. Rather than assume the solution to social exile for international students is more programming for international students, an internationalist perspective instead proposes programming that addresses international issues that include both domestic and international student populations. From a micro perspective, other authors acknowledge that the dynamic and fluid nature of identities and experiences require a more nuanced and intersectional approach to international student experiences. Authors consider the journeys of international students to conceive of three different types of migrants: the ambivalent migrant, the unwilling migrant, and the effortless migrant.

As stated by the editors, the aim of this edited volume is to "explore the diverse experiences that international student encounter when studying outside of their home countries, as well as the importance of such international encounters within higher education institutions more broadly, to better understand the challenges and opportunities of fostering meaningful cross-cultural engagement across the international divide," ( $\mathrm{p} 3$ ). The editors put forth the idea that if international student perspectives are examined in a comparative perspective, commonalities of 
experience, both positive and negative, can be examined in greater detail and opportunities to develop best practices and approaches for addressing specific encounters can be explored.

At times the approach taken by the authors throughout the book is onedimensional, relying solely on nationality as the determining factor of student experience, while other articles acknowledge that examining student sense-making from an intersectional lens could expand the research and literature in the field of international and transcultural higher education to create more vibrant portraits of the myriad of ways students cross borders, reflect the nuanced terrains of possibilities student envision for themselves, and illuminate the geography of the mind that all students encounter.

However, overall the collection of articles in International Encounter: Higher Education and the International Student Experience provides an opportunity to expand the reader's understanding of how international students experience border crossings in several English-speaking countries. While the authors unpack the lived experiences and sense-making of specific groups of international students, it is noted that the context, cultural identities, and the experiences of students before arriving in a host culture play an important part in cultural encounters, making generalizations difficult.

International Encounter: Higher Education and the International Student Experience is worthwhile reading for university administrators and faculty looking to create more inclusive campuses and classrooms, as well as graduate students researching or entering the field of student services. This collection of articles contributes to the growing efforts in the field to better understand how to create opportunities for domestic and international students to collaborate on an interpersonal level on college campuses.

TERRA GARGANO, Ph.D., teaches undergraduate and graduate courses in intercultural communication, international education, qualitative research design, and training program design. She spent time teaching English in Japan and was the Assistant Dean of Semester at Sea for ISE (the Institute for Shipboard Education) before serving as a faculty member at American University as well as the University of Maryland. She worked with the Intercultural Management Institute to organize conferences and conduct trainings for expatriates and their families, graduate students, and foreign nationals. Throughout her career in international education, she has managed dozens of study abroad programs and institutional collaborations worldwide. Email: terragargano@hotmail.com 